\title{
FUNGSI DAN BENTUK PENYAJIAN \\ MANTRA DAN KATAMBUNG DALAM RITUAL BALIAN MIMBUL KULUK METU SUKU DAYAK NGAJU DI KOTA PALANGKA RAYA
}

\author{
Zulfikar Muhammad Nugroho \\ Jurusan Etnomusikologi, Institut Seni Indonesia Yogyakarta \\ Email: zulfikarmuhammadnugroho@gmail.com
}

\begin{abstract}
Abstrak
Mantra dan katambung merupakan bunyi-bunyian yang terdapat dalam ritual balian mimbul kuluk metu suku Dayak Ngaju di Kota Palangka Raya. Masyarakat Dayak Ngaju meyakini bahwa ritual balian mimbul kuluk metu adalah wahana untuk menjaga keharmonisan alam semesta. Penelitian ini difokuskan pada dua hal, yaitu: (1) mengetahui fungsi dan (2) bentuk penyajian mantra dan katambung dalam ritual balian mimbul kuluk metu. Penelitian ini menggunakan metode kualitatif yang dipadukan dengan pendekatan etnomusikologis. Hasil penelitian ini menunjukan terdapat hubungan erat antara mantra-katambung dan ritual balian mimbul kuluk metu yang tercermin melalui fungsinya sebagai sarana ritual, persembahan simbolis, komunikasi vertikal, dan sarana integrasi masyarakat. Hubungan kompleksitas tersebut turut tergambarkan melalui bentuk penyajiannya yang meliputi struktur pertunjukan, aspek musikal, dan aspek non musikal. Struktur pertunjukan meliputi tiga tahapan, yaitu: tandak, mantra dan katambung, serta katambung mengiringi prosesi penanaman kepala kerbau (mimbul kuluk metu). Aspek musikal meliputi melodi (ruang) dan ritme (waktu), dan aspek non musikal meliputi tempat, waktu, sesajen, benda ritual, pelaku, dan kostum.
\end{abstract}

Kata kunci: fungsi, bentuk penyajian, mantra, katambung, balian mimbul kuluk metu, dayak ngaju

\begin{abstract}
Mantra and katambung are sounds found in the balian mimbul kuluk metu ritual, the Dayak Ngaju tribe in Palangka Raya City. The Ngaju Dayak community believes that the balian mimbul kuluk metu ritual is a vehicle for maintaining the harmony of the universe. This research is focused on two things, they are: (1) knowing the function and (2) the form presentation mantra and katambung in balian mimbul kuluk metu ritual. This study uses qualitative methods that are integrated with ethnomusicological approaches. The results of this study indicate that there is a close relationship between mantra-katambung and balian mimbul kuluk metu ritual which is reflected through its function as a means of ritual, symbolic, vertical communication, and community integration. The relationship of complexity is also illustrated through the form of its presentation which includes the structure of the performance, musical aspects, and non-musical aspects. The structure of the show includes three stages, they are: tandak, mantra and katambung, and katambung accompanying the procession of buffalo head planting (mimbul kulu metu). Musical aspects include melody (space) and rhythm (time), and non-musical aspects include place, time, offerings, ritual items, performers, and costumes.
\end{abstract}

Key words: mantra, katambung, balian mimbul kuluk metu, dayak ngaju 


\section{A. Latar Belakang}

Balian merupakan salah satu ritual keagamaan masyarakat Dayak Ngaju Hindu Kaharingan di Kota Palangka Raya. Ranying (Wawancara: 2019) mengatakan bahwa dalam mitologi Dayak Ngaju, balian telah ada bersamaan dengan diturunkannya semua ajaran Hindu Kaharingan kepada manusia. Balian dikenal memiliki beragam jenis, salah satu diantaranya adalah balian mimbul kuluk metu.

Balian mimbul kuluk metu merupakan ritual persembahan kepada penguasa bumi yang secara simbolis diwujudkan melalui aktivitas penanaman kepala hewan kurban. Balian mimbul kuluk metu termasuk bagian dari rangkaian upacara besar mamapas lewu (membersihkan kampung). Mitos yang berkembang di masyarakat Dayak Ngaju, bahwasanya aktivitas penanaman kepala hewan kurban sebagai bentuk persembahan kepada naga galang petak (penguasa alam bawah) merupakan salah satu faktor penentu keberlangsungan hidup masyarakat Dayak Ngaju di tahun-tahun mendatang. Lahirnya mitos tersebut bukan tanpa alasan, melainkan bersumber dari konsep kosmologi yang tertuang dalam wujud batang garing (pohon kehidupan) sebagai manifestasi pedoman hidup masyarakat Dayak Ngaju yang masih kuat diyakini hingga saat ini. Widodo (Wawancara: 2019) mengatakan bahwa masyarakat Dayak Ngaju percaya bahwa alam semesta ini terbagi menjadi tiga bagian, yaitu alam atas tempat bersemayamnya Ranying Hatala Langit (Tuhan), pantai danum kalunen atau alam tengah tempat tinggal manusia, dan alam bawah tempat bersemayamnya jata (di air) dan naga galang petak (di tanah). Menjaga keharmonisan ketiga alam tersebut merupakan suatu kewajiban bagi masyarakat Dayak Ngaju, apabila ritual ini tidak dilaksanakan, dikhawatirkan dapat memunculkan kemarahan dari penguasa alam atas maupun penguasa alam bawah. Upaya untuk menghindari kemarahan tersebut adalah dengan melaksanakan ritual balian mimbul kuluk metu setiap tahunnya.

Berdasarkan fenomena yang terindera dilapangan, ritual balian mimbul kuluk metu tidak sekedar menghadirkan sesajen, bendabenda sakral, dan pelaku ritual sebagai unsur primer yang kompleks. Namun, terdapat unsur primer lain yang kehadirannya patut diperhitungkan yaitu mantra dan katambung. Mantra adalah vokal suci yang dilantunkan basir (pelaku ritual) sembari diiringi katambung. Katambung merupakan alat musik berbahan kayu keras yang dilubangi pada bagian tengahnya, sumber suaranya berasal dari kulit reptil yang ditempelkan sejenis getah pada kulit tersebut sehingga menghasilkan bunyi yang khas, dan dimainkan dengan cara dipukul menggunakan telapak tangan.

Pada penyajiannya, mantra dan katambung dimainkan secara simultan oleh 
lima orang basir lengkap dengan seperangkat sesajen dan benda ritualnya. Selain balian mimbul kuluk metu, dalam upacara ritual mamapas lewu terdapat fenomena musikal lain yang memiliki perbedaan secara bentuk penyajian (musikal dan non musikal) seperti balian tantulak lapik gawi palus, balian mamapas lewu, balian najiret sahur, balian nasaran sahur kuman, balian mangkang sangiang, balian paturun sangiang, balian manjung takuluk metu, dan balian pambuli sangiang. Secara musikal perbedaan balian mimbul kuluk metu dengan balian lainnya terlihat dari syair mantra, melodi mantra, pola tabuhan katambung, dan struktur musikalnya. Secara non musikal perbedaan terletak pada wujud sesajen, benda ritual, waktu, dan tempat ritual.

Bagi masyarakat Dayak Ngaju beragama Hindu Kaharingan, ritual balian mimbul kuluk metu ini telah terbiasa dilaksanakan para basir dan telah menjadi sesuatu yang bersifat turun-temurun sejak bawi ayah mengajarkannya kepada manusia. Kehadiran mantra dan katambung sebagai wahana ritual dirasa sangat penting, mengingat keberadaannya masih dapat ditemukan dalam setiap ritual balian mimbul kuluk metu. Jika digelar ritual balian mimbul kuluk metu, secara otomatis lantunan mantra dan bunyi-bunyian katambung terdengar mengiringi, meramaikan, dan ikut berperan menyukseskan prosesi penanaman kepala hewan kurban yang sedang berlangsung.
Berdasarkan pengamatan di lapangan, belum pernah ditemui pelaksanaan ritual balian mimbul kuluk metu tanpa adanya lantunan mantra dan bunyi-bunyian katambung. Keduanya ibarat kedua sisi pada sebuah mata uang logam yang tak terpisahkan. Hal ini menimbulkan dugaan bahwa masyarakat Dayak Ngaju secara umum dan masyarakat Dayak Ngaju beragama Hindu Kaharingan secara khusus memandang mantra dan katambung dalam konteks ritual balian mimbul kuluk metu bukan sekedar sebagai praktik musikal pelengkap prosesi, tetapi mempunyai maksud dan tujuan yang sangat penting sehingga selalu dihadirkan dalam ritual.

Kehadiran mantra dan katambung sangat diyakini masyarakat Dayak Ngaju dapat mempercepat hubungan dengan alam gaib, karena mantra dan katambung bukanlah hasil produk manusia yang tinggal di bumi, melainkan hasil proses transmisi yang diajarkan langsung oleh bawi ayah (manusia langit utusan Ranying Hatalla Langit) kepada manusia. Fenomena musikal yang dihadirkan dianggap memiliki nilai sakral dan apabila digunakan dalam ritual balian mimbul kuluk metu akan mempermudah proses interaksi terhadap para sangiang yang ingin dihadirkan dan naga hai galang petak (dewa bumi) yang menjadi tujuan persembahan. Hal ini menjadi salah satu yang menjadi perhatian sehingga lahir keinginan untuk memahami secara lebih 
mendalam nilai guna serta bagaimana mantra dan katambung dalam ritual balian mimbul kuluk metu disajikan.

\section{Fungsi Manifes dan Laten}

Robert K. Merton mengemukakan konsep fungsi manifes dan fungsi laten sebagai sebuah instrument analisis fungsional. Fungsi manifes adalah fungsi yang bersifat eksplisit (intended), dan fungsi laten adalah fungsi yang bersifat implisit (non intended).

\section{B. Metode Penelitian}

Penelitian ini tergolong ke dalam penelitian kualitatif menggunakan pendekatan etnomusikologis dengan metode penulisan secara deskriptif analitis. Penelitian kualitatif dimulai dengan asumsi dan penggunaan kerangka penafsiran/teoritis yang membentuk atau memengaruhi studi tentang permasalahan riset yang terkait dengan makna yang dikenakan oleh individu atau kelompok pada suatu permasalahan sosial atau manusia (Creswell, 2015: 59).

Pendekatan yang digunakan adalah pendekatan etnomusikologis yaitu sebuah cara untuk melihat sebuah fenomena musikal dengan tidak menitikberatkan pada aspek musikalnya saja, namun turut menghubungkan musik tersebut dengan halhal yang mengitarinya, seperti masyarakat pendukungnya. Kajian etnomusikologi secara eksplisit dikemukakan oleh Shin Nakagawa meliputi aspek teks dan konteks. Teks diartikan sebagai kejadian akustik yang meliputi ritme, melodi, tempo maupun warna suara, sedangkan konteks adalah suasana, atau keadaan yang dibentuk oleh masyarakat pendukung musik tersebut (Nakagawa, 2000: 6). Hal ini kemudian dipertegas oleh Bruno Nettl yang mengatakan bahwasanya cara terbaik untuk memahami musik (teks) ialah dengan mengetahui konteks budayanya. Selain ihwal diatas, pendekatan etnomusikologis turut memperhatikan wilayah atau ruang lingkupnya sebagai paramater dasar sebuah studi etnomusikologi, yaitu: (1) musik dari masyarakat-masyarakat non literasi, (2) musik dari kebudayaan-kebudayaan tinggi Asia dan Afrika Utara-Cina, Jepang, Jawa, Bali, Asia Tenggara, India, Iran, dan negaranegara yang menggunakan bahasa Arab, dan (3) musik rakyat (Nettl, 2012: 5-7).

Dalam penelitian ini, keterlibatan dalam serangkaian aktivitas sebagai bagian proses pengumpulan data tidak terhindarkan. Adapun aktivitas tersebut meliputi: menentukan tempat/individu, memperoleh akses dan membangun hubungan, sampling purposeful, mengumpulkan data, merekam informasi, memecahkan persoalan lapangan, dan menyimpan data (Creswell, 2015: 207). Untuk menyajikan data agar mudah dipahami, maka langkah-langkah analisis data yang digunakan dalam penelitian ini 
adalah Analysis Interactive dari Miles dan Huberman, model ini membagi langkahlangkah analisis data menjadi beberapa bagian meliputi: pengumpulan data (data collection), reduksi data (data reduction), penyajian data (data display), dan penarikan kesimpulan atau verifikasi (conclutions).

\section{Hasil dan Pembahasan}

Berdasarkan studi literatur, dalam Panaturan, pasal 41 tentang bawi ayah hadurut bara lewu telu nanturung pantai danum kalunen (bawi ayah hadir di lewu telu menuju pantai danum kalunen) ayat 1-45, dikatakan bahwa mantra dan katambung merupakan bagian primer dari ritual balian sekaligus sebagai salah satu ajaran keagamaan Hindu Kaharingan yang bersumber dari sabda Ranying Hatalla Langit, yang kemudian ditransmisikan kepada bawi ayah sebagai utusan yang bertugas mengajarkan manusia tentang bagaimana melaksanakan sebuah ritual balian.

Berkenaan dengan naga hai galang petak, dalam Panaturan, pasal 2 ayat $1-2$ disebutkan bahwa naga hai galang petak merupakan makhluk pertama yang diciptakaan Ranying Hatalla Langit.

Berikut uraian hasil dari observasi, dokumentasi, serta wawancara terhadap fenomena musikal mantra dan katambung dalam konteks ritual balian mimbul kuluk metu suku Dayak Ngaju di Kota Palangka Raya.

Balian mimbul kuluk metu adalah ritual penanaman kepala hewan kurban yang dipimpin oleh seorang basir yang dibantu oleh empat basir panggapit, sembari melantunkan mantra dan menabuh katambung. Sesajen yang digunakan sebagai persembahan adalah kepala kerbau. Kepala kerbau ini dipersembahkan untuk naga hai galang petak selaku penguasa tertinggi alam bawah.

\section{Tahapan Ritual Balian Mimbul Kuluk Metu}

\section{Persiapan}

Persiapan merujuk pada serangkaian aktivitas lima orang basir dan asistennya dalam rangka mempersiapkan hal-hal yang diperlukan untuk menyukseskan pelaksanaan ritual balian mimbul kuluk metu.

1 Januari 2019, pukul 08.20 Wib, aktivitas berlangsung di dalam rumah adat Dayak Betang Hapakat, para basir mempersiapkan katambung yang akan digunakan untuk ritual, pada waktu bersamaan asisten basir mempersiapkan seluruh sarana ritual, seperti sesajen dan benda ritual. Aktivitas persiapan berlanjut pukul 08.45 Wib yakni penurunan katambung, sarana ritual dan seperangkat sesajen yang akan dipersembahkan kepada naga hai galang petak dari dalam rumah adat Betang Hapakat menuju halaman depan 
tempat ritual balian mimbul kuluk metu dilaksanakan.

\section{Pertunjukan Mantra dan Katambung}

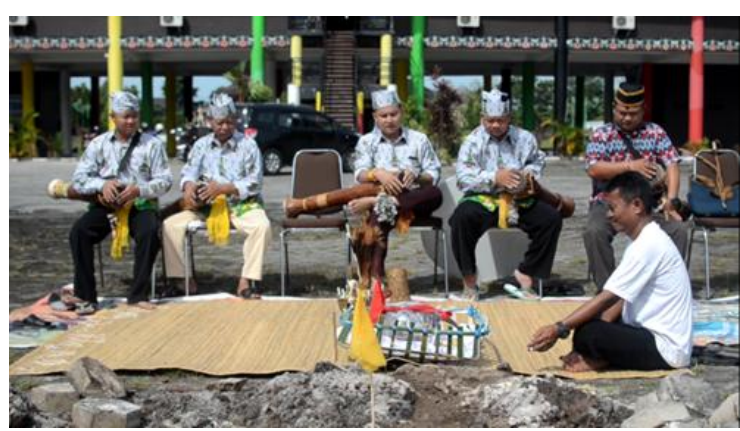

Gambar 1. Pertunjukan mantra dan katambung (Zulfikar Muhammad Nugroho, 2019)

Pukul 09.00 Wib pertunjukan dimulai. Basir upu mengawali pertunjukan dengan melantunkan tandak atau lantunan do'a suci. Setelah tandak berakhir, seluruh basir (upu dan panggapit) secara serentak melantunkan mantra dengan diiringi tabuhan katambung. Secara totalitas, durasi pertunjukan kurang lebih 9 menit. Pertunjukan mantra dan katambung berakhir ketika syair/lirik mantra telah selesai dilantunkan semua. Basir panggapit menjadi pelantun yang mengakhiri syair/lirik tersebut, sebelum pada akhirnya terdapat tutti (tanda) dari katambung sebagai penanda pertunjukan mantra dan katambung selesai dengan sempurna. Aktivitas berlanjut ke prosesi manawur.

\section{Manawur}

Manawur dilakukan oleh basir upu. Aktivitas manawur diiringi oleh tabuhan katambung. Katambung dimainkan oleh tiga orang basir panggapit. Satu basir panggapit lainnya membantu menyiapkan benda dan sesajen ritual yang belum tertata dengan baik.

Secara etimologi, manawur berarti menabur. Benda yang ditaburkan adalah beras. Beras ditaburkan sejumlah 4 (empat) kali ke arah lubang tempat kepala kerbau akan ditanam/dikuburkan. Beras yang digunakan untuk manawur ini adalah beras biasa (bukan ketan), berwarna putih, dan tidak melalui proses pewarnaan atau sejenisnya.

\section{Tampung Tawar I}

Setelah manawur, prosesi selanjutnya adalah tampung tawar. Tampung tawar adalah ritual untuk membersihkan hal-hal yang bersifat tidak baik atau negatif. Masih diiringi katambung, prosesi tampung tawar dijalankan oleh basir upu. Wujud prosesi ini adalah memercikkan air suci 2 (dua) kali ke arah kepala kerbau, dan 3 (tiga) kali ke arah lubang tepat tempat kepala kerbau akan ditanam/dikuburkan.

\section{Memasukkan Kepala Kerbau ke dalam Lubang Persembahan}

Masih diiringi tabuhan katambung, 2 (dua) orang asisten basir mengangkat seperangkat sesajen yang dipersembahkan kepada naga hai galang petak (penguasa bumi) menuju lubang penguburannya. Ketika seperangkat sesajen berada tepat di 
atas lubang penguburan, ketua umum Majelis Besar Agama Hindu Kaharingan (MB-AHK) Provinsi Kalimantan Tengah merobek atau menyayat plastik yang membungkus kepala kerbau dengan menggunakan mandau. Belum diketahui sejak kapan tradisi kepala kerbau sebelum ditanam terlebih dahulu harus dibungkus menggunakan plastik. Setelah disayat, mandau tersebut diangkat ke atas dengan posisi ujung mandau mengarah ke langit sambil membaca mantra secara lirih. Setelah itu, mandau disentuhkan ke kepala kerbau untuk membantu mengarahkan proses penurunan seperangkat sesajen menuju ke dalam lubang.

Setelah seperangkat sesajen telah berada di dasar lubang, ketua umum Majelis Besar Agama Hindu Kaharingan (MB-AHK) Provinsi Kalimantan Tengah mengangkat mandau ke atas, sehingga ujung mandau tersebut menghadap ke langit, sembari manukiu (vokal bersyair: “Oooooooooo...ooooo... Kiew!”) sebanyak 3 (tiga) kali. Di sisi lain, saat ketua umum MBAHK manukiu, basir upu membacakan mantra sembari memegang seperangkat sarana ritual yaitu mangkuk bening lengkap dengan isinya. Ketika manukiu selesai, maka berakhir pula tabuhan katambung.

\section{Tampung Tawar II}

Setelah tabuhan katambung berhenti, pembacaan mantra oleh basir upu selesai, lalu dilakukan tampung tawar yang kedua. Tampung tawar dilakukan 2 (dua) kali, pertama oleh basir upu sebanyak 7 (tujuh) percikan, dan kedua oleh ketua umum Majelis Besar Agama Hindu Kaharingan sebanyak 5 (lima) percikan.

\section{Penguburan Kepala Kerbau}

Tahapan terakhir dari ritual balian mimbul kuluk metu adalah pelemparan tanah sebanyak 3 (tiga) kali seusai kepala kerbau sempurna berada di dasar lubang, diawali oleh basir, Ketua Adat, dan kemudian seluruh masyarakat yang hadir. Aktivitas ini bermakna sebagai bentuk pengharapan kepada Ranying Hatalla Langit agar apapun yang kita inginkan di tahun yang baru ini dapat segera tercapai dan dikabulkan

\section{Fungsi Mantra dan Katambung dalam Ritual Balian Mimbul Kuluk Metu}

\section{Sarana Ritual}

Pengukuhan mantra dan katambung sebagai sarana primer berwujud bunyibunyian dalam konteks ritual balian mimbul kuluk metu dilatarbelakangi setidaknya oleh dua alasan. Alasan pertama, mantra dan katambung merupakan ajaran Ranying Hatalla Langit yang ditransmisikan oleh bawi ayah kepada umat manusia. Pandangan pertama ini lebih bersifat mitologis, dan alasan kedua berdasarkan fakta yang terindera dilapangan yaitu terdapat aspekaspek yang mengitari mantra dan katambung 
sebagai sebuah sistem kesatuan dalam ritual balian mimbul kuluk metu yang kompleks.

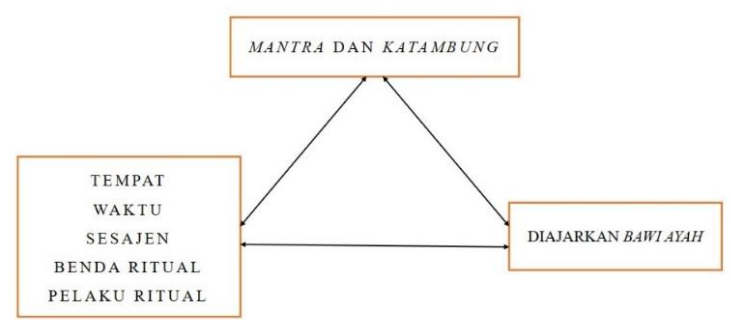

Skema 1.

Mantra dan katambung sebagai sarana ritual. (Kontruksi oleh: Zulfikar Muhammad Nugroho, 2019)

Alasan pertama mengacu pada asal mula ritual balian yang ajarkan langsung oleh bawi ayah kepada anak cucu Raja Bunu (manusia pertama dalam mitologi Dayak Ngaju Hindu Kaharingan). Ajaran ini diperintahkan langsung oleh Ranying Hatalla Langit kepada bawi ayah untuk selanjutnya ditransmisikan kepada umat manusia.

Alasan kedua, mengapa mantra dan katambung dapat dikatakan sebagai sarana ritual, adalah karena mantra dan katambung dihadirkan dalam sebuah jalinan sistem yang meliputi aspek waktu, tempat, sesajen, benda-benda sakral, dan pelaku ritual. Aspek-aspek yang membentuk sebuah kesatuan sistem mantra dan katambung dalam ritual balian mimbul kuluk metu tersebut merupakan ciri-ciri sebuah pertunjukan ritual dalam Dayak Ngaju.

Berdasarkan dua alasan tersebut, kedudukan mantra dan katambung sebagai sarana dalam ritual balian mimbul kuluk metu suku Dayak Ngaju Hindu Kaharingan di Kota Palangka Raya secara eksplisit dapat tergambarkan melalui proses transmisi ajaran Hindu Kaharingan (balian) dari bawi ayah kepada umat manusia serta aspek-aspek non musikal yang termuat sebagai unsur dalam penyajiannya.

\section{Persembahan Simbolis}

Masyarakat Dayak Ngaju khususnya yang beragama Hindu Kaharingan mengamini bahwa aktivitas penanaman kepala kerbau ini sebagai sebuah persembahan simbolis yang wajib dilaksanakan setiap tahunnya. Kehadiran lantunan mantra dan tabuhan katambung menyiratkan bahwa persembahan ini tidak dapat dipahami dari aspek eksplisitnya saja (kepala kerbau), namun aspek implisit (mantra dan katambung) juga merupakan persembahan simbolis yang ditujukan kepada para sangiang yang diundang untuk hadir dalam ritual.

Kompleksitas mantra-katambung dan kepala kerbau sebagai material yang disuguhkan masyarakat Dayak Ngaju kepada naga hai galang petak adalah wujud upaya menjaga keharmonisasian kosmosnya.

\section{Sarana Komunikasi Vertikal}

Fungsi mantra dan katambung sebagai sarana komunikasi vertikal ditujukan ke dunia atas dan dunia bawah. Dunia atas 
tempat bersemayamnya Ranying Hatalla Langit beserta para sangiang (utusannya) seperti raja mantir mama luhing bungai, dan dunia bawah tempat bersemayamnya naga hai galang petak.

Komunikasi vertikal ke dunia atas dilakukan para basir melalui mantra dan tabuhan katambung, yang mana dalam syair mantra tersebut mengandung ungkapan dan keinginan para basir agar kiranya raja mantir mama luhing bungai membantu mereka menyukseskan pelaksanaan ritual balian mimbul kuluk metu.

Komunikasi vertikal ke dunia bawah dapat dilihat juga dari lantunan mantra dan katambung yang di dalamnya mengandung makna bahwa sesajen kepala kerbau ini kami persembahkan kepadamu wahai naga hai galang petak (penguasa bumi) agar engkau kiranya melindungi dan memberi keselamatan kepada kami masyarakat Kota Palangka Raya dalam mengarungi bahtera kehidupan di dunia ini.

\section{Sarana Integrasi Masyarakat}

Mantra dan katambung tidak terpisahkan dari masyarakat Dayak Ngaju khususnya yang beragama Hindu Kaharingan dalam berbagai macam aktivitas ritualnya. Mantra dan katambung menjadi media pemersatu yang mampu menciptakan semangat persatuan, handep hapakat (gotong-royong), dan rasa persaudaraan. Hal ini terpancar dari aktivitas pra ritual balian mimbul kuluk metu, seperti menyiapkan konsumsi, menyembelih hewan kurban, membantu mengangkat instrumen katambung dan seperangkat sesajen dari rumah betang (rumah tradisional Dayak Ngaju) ke tempat = ritual balian mimbul kuluk metu, dimana di dalamnya segala aktivitas tersebut melibatkan masyarakat, baik yang beragama Hindu Kaharingan maupun tidak.

\section{Bentuk Penyajian Mantra dan Katambung dalam Ritual Balian Mimbul Kuluk Metu}

\section{Aspek Musikal}

\section{a. Analisis Struktur Musikal}

1) Tandak

Tandak merupakan vokal yang disajikan tanpa ada iringan (instrumen). Tandak yang dilantunkan oleh basir upu ini berisi tentang do'a untuk mempersembahkan kepala kerbau kepada naga hai galang petak.

Dilihat dari aspek waktu, pertunjukan tandak berdurasi 1 menit 42 detik dengan tempo \pm 57 M.M.. Bagian ini menggunakan metrum (sukat) jenis freemetric atau bebas tempo. Selain waktu, aspek ruang yang terdapat dalam pertunjukan tandak adalah tangga nada. Tandak termasuk dalam klasifikasi tangga nada kromatis.

\section{2) Mantra dan Katambung}

Secara umum, mantra dan katambung merupakan lagu yang termasuk dalam lagu 3 bagian. Struktur musik mantra dan katambung diawali dengan tabuhan katambung (introduction), lalu masuk ke mantra dan katambung bagian 1A. Berikut 
melodi mantra yang dilantunkan basir upu tanpa menyertakan syair/lirik secara utuh, diperkenankan untuk ditulis selain untuk kebutuhan upacara ritual.

karena syair (lirik) mantra tidak

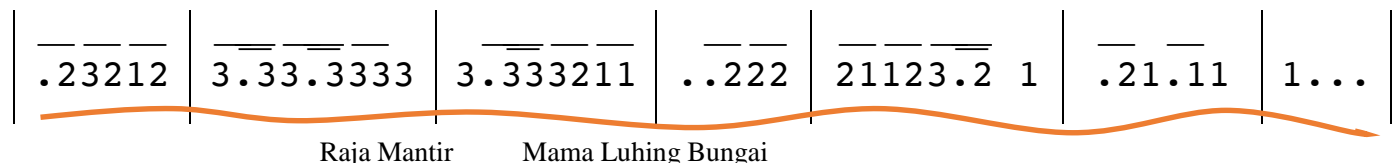

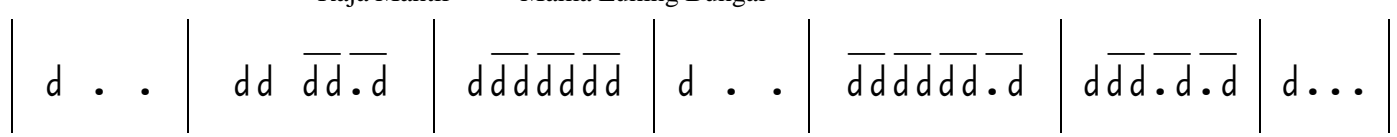

Setelah basir ири selesai, lantunan yang dilantunkan oleh basir uри mantra langsung dilanjutkan basir panggapit sebelumnya.

dengan menggunakan lirik yang sama seperti

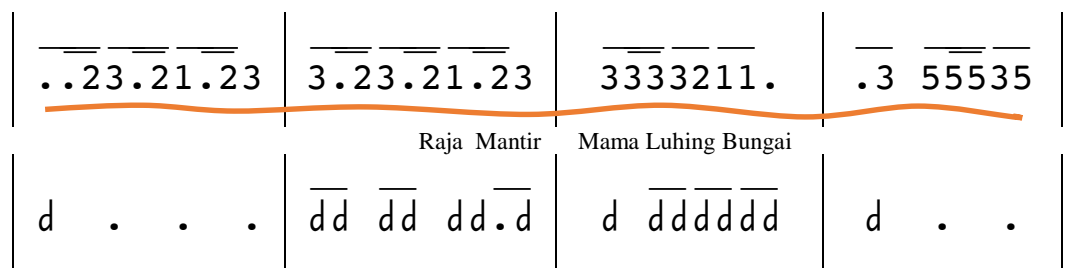

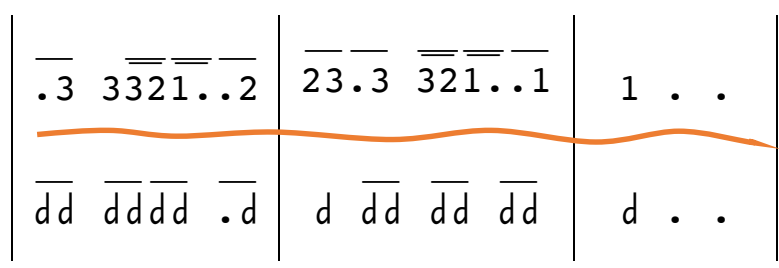

Setelah basir panggapit selesai, basir diulang sebanyak 2 kali. Bagian 1A ири kembali melantunkan mantra yang berjumlah 69 bar. Setelah di-repetisi, lalu kemudian dilanjutkan oleh basir panggapit. masuk ke bagian 1B. Berikut notasinya:

Mantra dan katambung bagian 1A ini

\begin{tabular}{l|c|c|r|}
$\overline{.232} \overline{12}$ & $333 \overline{33} \overline{33}$ & $3 \overline{.33} \overline{32} \overline{11}$ &.$\overline{2} \overline{22}$ \\
\hline$d .$. & $d d \overline{d d} \bar{d}$ & $d \overline{d d} \bar{d} \bar{d} \bar{d}$ & $d \quad . \quad$
\end{tabular}

\begin{tabular}{|c|c|c|}
$\overline{21} \overline{123 \overline{.2}} 1$ & $\overline{21} \overline{12 \overline{3.2}} 1$ & $\overline{2112 \overline{3.2}} 1$ \\
\hline $\bar{d} \bar{d} \bar{d} \bar{d} \bar{d} \overline{. d}$ & $d \overline{d d} \bar{d} \overline{d . d}$ & $d$
\end{tabular} \mid

(cuplikan notasi mantra dan katambung basir upu) 


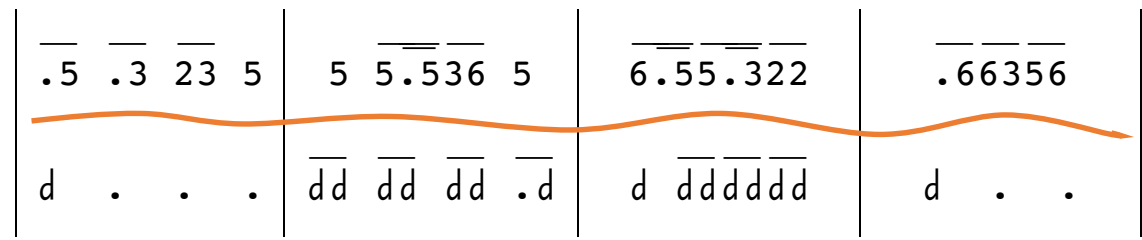

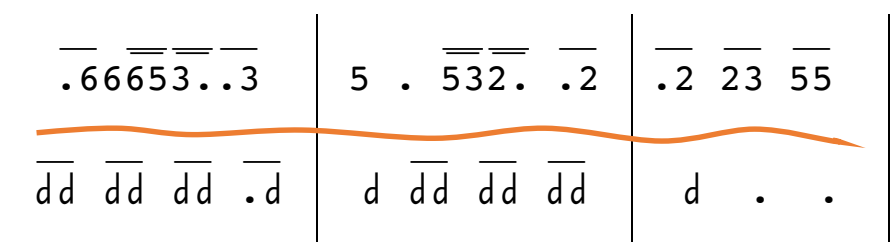

(cuplikan notasi mantra dan katambung basir panggapit)

\begin{tabular}{|c|c|c|c|c|c|}
\hline $.2 \overline{2355}$ & $\overline{. .2} \overline{333} \overline{435}$ & $.2 \overline{21} \overline{21} \overline{21}$ & $\overline{123.3} \overline{3121}$ & $1 . \overline{11}$ & $1 \ldots$ \\
\hline . & $\overline{d d} \overline{d d} \overline{d d} \cdot \bar{d}$ & $d \quad d \quad d$ & $d \quad d \quad d$ & $d d d d$ & $d d d d$ \\
\hline
\end{tabular}

(cuplikan notasi mantra dan katambung basir upu)

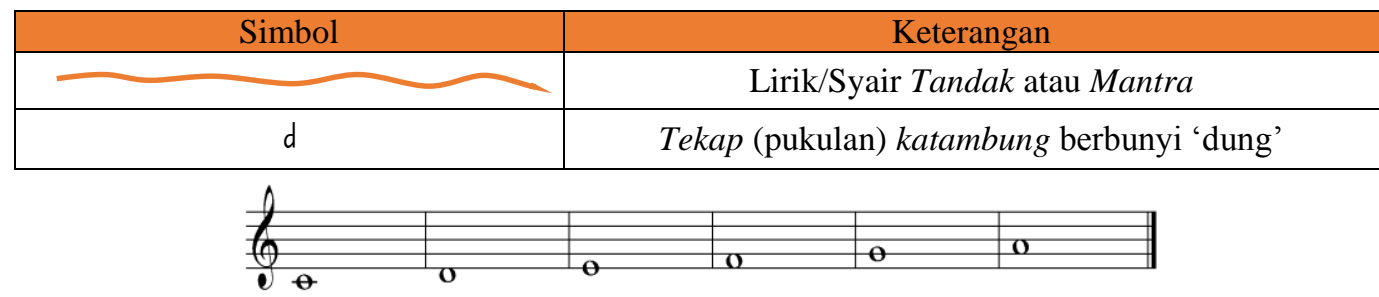

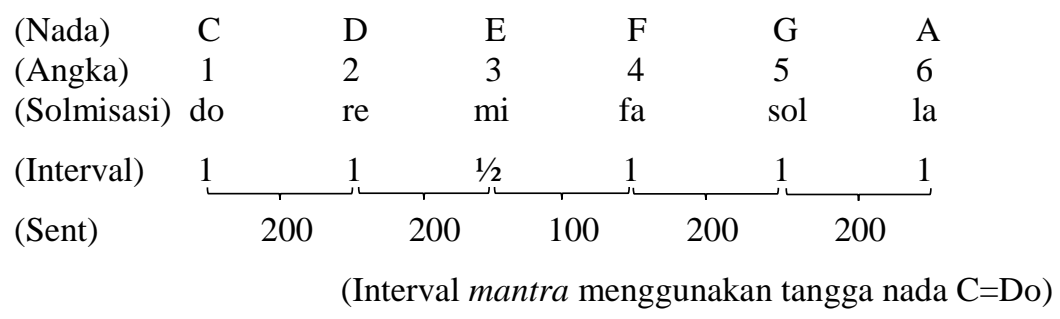

Transisi (berubah irama katambung) menandai perpindahan musik mantra dan katambung ke bagian 2A. Dilihat dari aspek waktu, durasi mantra dan katambung bagian 1 (satu) adalah 4 menit 7 detik, tempo yang digunakan dalam bagian ini (1) adalah \pm 100 M.M., didominasi oleh satu jenis metrum (sukat) namun terkadang diselingi sukat berbeda, disebut dengan heterometric. Selain aspek waktu, terdapat aspek ruang dalam pertunjukan mantra dan katambung bagian 1 (satu), yaitu tangga nada. Mantra bagian 1 (satu) termasuk dalam klasifikasi tangga nada pentatonik (lima nada), atau dapat juga disebut pentatonik anhemitonik sama seperti slendro dalam tangga nada karawitan Jawa.

Pertunjukan berlanjut ke mantra dan katambung bagian 2A. Mantra dan katambung bagian 2A berjumlah 33 bar. Setelah itu masuk ke bagian 2B. 
Dilihat dari aspek waktu, pertunjukan mantra dan katambung bagian 2 (dua) berdurasi 2 menit 41 detik dengan tempo \pm 149 M.M.. Bagian ini menggunakan metrum (sukat) jenis isometric. Selain waktu, terdapat aspek ruang dalam pertunjukan mantra dan katambung bagian 2 (dua) yaitu tangga nada. Mantra bagian 2 (dua) termasuk dalam klasifikasi tangga nada heksatonik (enam nada).

Pertunjukan berlanjut ke mantra dan katambung bagian 3. Mantra dan katambung bagian 3 ini diulang sebanyak 3 kali. Total bar pada bagian 3 adalah 24 bar. Dilihat dari aspek waktu, pertunjukan mantra dan katambung bagian 3 (tiga) berdurasi 1 menit 46 detik dengan tempo \pm 151 M.M.. Bagian ini menggunakan metrum (sukat) jenis heterometric. Selain waktu, aspek ruang yang terdapat dalam pertunjukan mantra dan katambung bagian 3 (tiga) adalah tangga nada. Mantra bagian 3 (tiga) termasuk dalam klasifikasi tangga nada heksatonik (enam nada) sama seperti mantra bagian 2.

\section{3) Katambung Mengiringi Prosesi}

\section{Penanaman Kepala Kerbau}

Prosesi penanaman kepala kerbau dipimpin oleh basir ири. Pada pelaksanaannya, basir upu dibantu dleh satu orang basir panggapit, Ketua Adat, dan dua orang asisten basir. Berikut transkrip cuplikan salah satu pola katambung (repetitif) saat mengiringi proses penanaman kepala kerbau.

$$
d \overline{d d} \overline{\cdot d} d|d \overline{d d} \overline{\cdot d} d|
$$

\section{b. Analisis Syair Mantra}

\section{Syair 1:}

"Raja Mantir Mama Luhing Bungai...."

Disebutkan 1 (satu kali), yaitu pada mantra dan katambung bagian 1A.

\section{Penjabaran:}

Raja Mantir Mama Luhing Bungai merupakan utusan Ranying Hatalla Langit yang diturunkan ke Pantai Danum Kalunen untuk menolong umat manusia saat melaksanakan ritual balian.

Penyebutan "Raja Mantir Mama Luhing Bungai" bermakna pemanggilan Raja Mantir Mama Luhing Bungai sebagai sangiang (manusia langit) utusan Ranying Hatalla Langit agar dapat hadir ke tempat ritual sebagaimana tugasnya adalah membantu basir ketika melaksanakan ritual balian mimbul kuluk metu di pantai danum kalunen atau bumi.

\section{Syair 2:}

"Naga Hai Galang Petak...."

Disebutkan sebanyak 3 (tiga) kali, yaitu pada mantra dan katambung bagian 1A satu kali, mantra dan katambung bagian 2A satu kali, dan mantra dan katambung bagian 3 satu kali.

\section{Penjabaran:}

Naga hai galang petak merupakan penguasa tertinggi alam bawah. Naga hai galang petak merupakan tujuan 
persembahan dalam ritual balian mimbul kuluk metu. Naga hai galang petak dipercaya sebagai penjaga alam manusia, agar manusia selamat dan terhindar dari segala marabahaya, persembahan berwujud seperangkat sesaji kepala kerbau mutlak dilakukan.

\section{Syair 3:}

"Kuluk Hadangan...."

Disebutkan 1 (satu) kali, yaitu pada mantra dan katambung bagian 2 .

\section{Penjabaran:}

Kuluk hadangan berarti kepala kerbau. Kuluk hadangan merupakan sesajen yang dipersembahkan untuk naga hai galang petak. Bagi masyarakat Dayak Ngaju, kerbau merupakan hewan kurban yang menyandang strata tertinggi, diikuti sapi, babi, dan ayam.

\section{Aspek Non Musikal}

\section{Tempat}

Ritual balian mimbul kuluk metu bertempat di halaman Rumah Adat Dayak Betang Hapakat yang berada di Jln. R.T.A Milono, Km. 4. Kota Palangka Raya.

\section{Waktu}

Waktu pelaksanaan ritual balian mimbul kuluk metu adalah hari selasa, 1 Januari 2019, pukul 09.00 - 09.20 Wib.

\section{Sesajen}

Sesajen ritual yang dimaksudkan disini adalah sesajen yang dikubur atau dipersembahkan ke naga hai galang petak yang meliputi: (1) Kuluk Hadangan (kepala kerbau); (2) Bendera Bahandang (merah); (3) Danum Baputi (air putih); (4) Pisang Luntuh (rebus); (5) Tanteluh Manuk (telur ayam); (6) Giling Pinang (buah pinang) \& Rukun Tarahan (rokok); (7) Ketupat \& Wadai Cucur (kue cucur); (8) Benang Lapik Kuluk Hadangan (alas kain kepala kerbau); dan (9) Ancak Mihing (tempat menaruh sesajen).

\section{Benda Ritual}

Benda ritual merujuk pada benda-benda yang memiliki guna serta fungsi ketika ritual balian mimbul kuluk metu dilaksanakan. Benda ritual tersebut antara lain: (1) Mandau (senjata khas suku Dayak); (2) Sangku (wadah sesajen berbahan kuningan); (3) Kalangkang Garu (sejenis anyaman rotan); (4) Hampatung Palawi (patung); (5) Dandang Tingang (bulu burung tingang/enggang); (6) Behas (beras); (7) Dohong (senjata khas basir); (8) Seperangkat alat Tampung Tawar; (9) Behas Hambaruan (beras pilihan; (10) Duit Singah Hambaruan (uang koin); (11) Sipa (sirih, pinang) dan Ruku (rokok); (12) Bendera Bahenda (kuning); (13) Amak (alas/tikar); dan (14) Kursi.

\section{Pelaku Ritual}

Pelaku dalam ritual balian mimbul kuluk metu meliputi: (1) Ketua Adat; (2) Basir; dan (3) Asisten Basir. 


\section{Kostum}

Ritual balian mimbul kuluk metu, kostum merujuk pada pengertian pakaian yang digunakan basir ketika melaksanakan ritual. Unsur-unsur yang disebut kostum tersebut, meliputi: (1) Lawung (penutup kepala); (2) Bahalai Bahenda (selendang kuning); (3) Lilis/Lamiang (sejenis manik-manik); (4) Baju Batik Bermotif Batang Garing (pohon kehidupan); dan (5) Galang Bahenda (gelang kuning).

\section{Simpulan}

Ritual balian mimbul kuluk metu merupakan prosesi wajib sebagai rangkaian dari upacara ritual mamapas lewu. Hal ini dapat dipahami dari maksud dan tujuan dilaksanakan ritual tersebut, yaitu sebagai bentuk ungkapan syukur atas penyertaan dan keselamatan yang telah diberikan oleh naga hai galang petak sehingga Kota Palangka Raya aman dari berbagai bencana alam, malapetaka, musibah, hingga pengaruhpengaruh buruk bersifat metafisika yang dapat mengganggu masyarakat.

Kehadiran mantra dan katambung menegaskan bahwa keduanya merupakan salah satu faktor penting suksesnya pelaksanaan ritual balian mimbul kuluk metu. Hal ini mengindikasikan bahwa mantra dan katambung memiliki nilai guna atau fungsi. Terdapat fungsi manifes dan laten mantra dan katambung dalam ritual balian mimbul kuluk metu, yaitu sebagai sarana ritual, persembahan simbolis, komunikasi vertikal, dan sarana integrasi masyarakat.

Dilihat dari aspek bentuk penyajiannya, diperoleh bahwa struktur pertunjukan mantra dan katambung terdiri dari tiga tahapan, yaitu tandak, mantra dan katambung, dan katambung saat mengiringi prosesi penanaman kepala kerbau. Selain itu, bentuk penyajian mantra dan katambung turut memuat aspek musikal dan nonmusikal. Aspek musikal meliputi aspek ruang (melodi) dan waktu (ritme), sedangkan aspek non-musikal meliputi tempat, waktu, sesajen, benda ritual, pelaku, dan kostum.

\section{E. Daftar Pustaka}

Bakar, Seth, Siren F, Rangka, Gani T. Andin. 1986/1987. Peralatan Hiburan dan Kesenian Tradisional Daerah Kalimantan Tengah. Jakarta: Direktur Jenderal Kebudayaan Departemen Pendidikan dan Kebudayaan.

Barier, Georg Martin. 2014. "Agama Hindu Kaharingan Sebagai Nativisme Sesudah Pengaruh Kristen Menjadi Peristiwa Yang Tak Ada Tandingannya", dalam Jurnal Simpson. Volume 1. Nomor 2. Desember.

Miles, Matthew B., A. Michael Huberman. 2009. Analisis Data Kualitatif: Buku Sumber Tentang Metode-Metode Baru Terj. Tjetjep Rohendi Rohidi. Jakarta: UI Press.

Creswell, John W. 2015. Penelitian Kualitatif \& Desain Riset Terj. Ahmad Lintang Lazuardi. Yogyakarta: Pustaka Pelajar. 
Koebek Dandan Ranying, Lewis, Simal Penyang, Walter S. Penyang, Bajik R. Simpei, Mantikei R. Hanyi, Rangkap I. Nau, Hanno Kampffmeyer, Yerson. 2009. Panaturan. Denpasar: Penerbit Widya Dharma.

Kuri, I Putu Gelgel, I Wayan Budi Utama. 2018. "Basir in Religious System of Dayak Hindu Kaharingan Society", dalam International Journal of Social Sciences and Humanities, Vol 2, No. 2, August, pages 164-174.

Nakagawa, Shin. 2000. Musik dan Kosmos Sebuah Pengantar Etnomusikologi. Jakarta: Yayasan Obor Indonesia.

Nau, Rangkap I. 2003. Buku Kandayu Penuntun Persembahyangan. Palangka Raya: Mejelis Besar Agama Hindu Kaharingan Pusat.

Nettl, Bruno. 2012. Teori dan Metode dalam Etnomusikologi. Terj. Natha H. P. Dwi Putra. Jayapura: Jayapura Center of Music.

Nur Rahmawati, Neni Puji. 2013. "Upacara Adat Mamapas Lewu", dalam Jantra, Vol. 8, No. 2, Desember.

Riwut, Tjilik. 2015. Maneser Panatau Tatu Hiang - Menyelami Kekayaan Leluhur. Yogyakarta: NR Publishing.

Soedarsono, R.M. 2001. Metodologi Penelitian Seni Pertunjukan dan Seni Rupa. Bandung: Masyarakat Seni Pertunjukan Indonesia.

Sugiyarto, Wakhid. 2016. "Eksistensi Agama Hindu Kaharingan di Palangka Raya", dalam Harmoni: Jurnal Multikultural \& Multireligius. Vol. 15. No.3. September-Desember.
Ugang, Hermogenes. 2010. Menelusuri Jejek-Jejak Keluhuran. Kalimantan Tengah: Lembaga Dayak Panarung.

William P. Malm. 1967. Music Cultures of The Pasific, The Near East and Asia. New Jersey: Prentice-Hall, Inc.

Mahin, Marko. 2006. "Kaharingan: Dinamika Agama Dayak di Kalimantan Tengah". Disertasi untuk menempuh derajat S-3 Antropologi Fakultas Ilmu Sosial dan Politik Departemen Antropologi Program Studi Pascasarjana Universitas Indonesia.

\section{Narasumber}

Parada Lewis Koebek Danum Ranying S.Ag., M.Si., 50 tahun, Ketua Majelis Hindu-Kaharingan Pusat Palangka Raya, Kota Palangka Raya.

Rabiadi, S.Sos.H., M.Pd.H., 32 tahun, Basir, Rohaniawan Hindu-Kaharingan, Dosen, Kota Palangka Raya.

Fransiskus Widodo, 31 tahun, Basir, Rohaniawan Hindu-Kaharingan, Swasta, Kota Palangka Raya. 